of air by calcium chloride. The authors have investigated the appliances necessary for drying large volumes of air and an appliance has been installed at the Differdauge Steelworks, Luxemburg, where it is now in normal working. In this process, the volume of air to be dried is made to traverse a mass of calcium chloride by means of a fan. Water is circulated through pipes bedded in the calcium chloride for the purpose of carrying away the heat generated by the absorption of water by the chloride. The hydration of the calcium chloride is arrested when the outside pellicle of the broken pieces commences to liquate, and a regeneration operation is employed for the purpose of rendering the calcium chloride capable of being employed for desiccating fresh volumes of air.

\section{THE INTERNATIONAL PHILOSOPHICAL CONGRESS AT BOLOGNA.}

$T^{\mathrm{HE}}$ fourth International Congress, which met at 1 Bologna under the presidency of Prof. Enriques, was formally opened on April 6 by the Duke of the Abruzzi. It has been by far the best attended of the series, the total number of members being more than five hundred, and has been most hospitably entertained by the committee and the various municipalities. The general tone of the debates was much more cordial than usual, and the congress was fortunate even in its conclusion, for the next day a general strike was declared in the town and province.

It is difficult to say what exactly we should expect from such gatherings. It is clear that they can never produce any definite result; but the contact of personalities does sometimes bring into clearer light the existence of general tendencies of thought which otherwise might not have been so definitely perceived. This congress did bring to light the existence of such a tendency, and this was the quite evident "decline in the importance of "system" in metaphysics. Philosophy does seem to be steering away from its traditional form. It is beginning to form a more fluent and a less rigid and systematic conception of truth. The working out of this tendency is connected with and was most clearly shown in the discussions of what really formed the main problem of the congress, the one it has spent the most time over-that of the relations between philosophy and science. This problem practically resolves itself into the question as to whether philosophy has any right to an independent existence, and it is perhaps one of the surest signs of the renaissance and vitality of the subject that it can discuss such a question with enthusiasm. This key-note of the congress was struck by Prof. Boutroux in his opening speech. Charming though this was in manner, it was not remarkable for profundity of thought, and offered no more original solution than that science, quite legitimately for its purposes, considered the world impersonally, and that it was the business of philosophy to reintroduce for a complete synthesis the element which science left out.

The same subject formed the theme the following day of a paper by that picturesque personality, Fra Gemelli, monk, biologist, and editor of the Revista Nee-Scolastica, which drew a reply from Prof. Hans Driesch, in which he explained the scientific use of his conception of entelechy, as distinct from Aristotle's more metaphysical use. The same subject continued to be discussed each day, until the debate finally culminated in the lecture, that was awaited with the greatest curiosity, that which was given by Prof. Henri Bergson, who is perhaps the most discussed and the most interesting philosopher in Europe at the present time. The main point he tried to establish in his conférence was that there were two different, and indeed inverse, ways of acquiring a knowledge of reality, the one that of scientific analysis, and another which he described as a kind of intuition, which should be the method of philosophy. Unfortunately, however, this is not the conception that philosophy has formed of itself. It has always attempted to use the same method as the science of its day; it has always attempted to do for the world in general what particular sciences have done for particular fields. It has conceived itself as the complete science, and therein lies the reason of its failure.

NO. 2 I 68 , VOL. 86$]$
This is true historically; Greek philosophy is nothing but the extension into a different field of the method which prevailed in the science of the times, that of geometry. We get a similar phenomenon in modern philosophy. For the static geometrical concepts of the Greek, substitute the conception of scientific law, extend this to the general problem of reality as the Greeks did goometry, and you get the predominant types of modern philosophy. Always you get philosophy pursuing the same method as that of science, that of intellectual analysis, and having the same ideal, that of a complete science of existence. Now, said Bergson, philosophy, so long as it persists in following this method, is doomed to disappear, for it being obviously not wanted in the field of any particular and successful science, it must pursue its activities in the fields where science has not yet penetrated, i.e. in the field of the unknown; and this is not a very secure position for it, for as soon as science begins to penetrate the same field, and there is a contradiction between its conclusions and the conclusions of philosophy, it is philosophy that must give way, not science.

The only future of philosophy, then, lies in a recognition of the fact that it must pursue a different method entirely to that of science. It must give up the attempt to give a complete intellectual representation of the cosmos. There remains the allied question of the place of system in philosophy. Looking at the extraordinary complicated constructions of the great systematic philosophers, they certainly seem to have been animated by the conviction that they were creating a science of the real. But, said Bergson, that is only superficial appearance. If you study, say, Spinoza long enough, you will find that the whole elaborate system was merely the language by which he expressed one perfectly simple intuition, a thing which would be stated in one sentence if you yourself had been in a similar state and could at once recognise it. Here comes, then, the absurdity of explaining a philosopher by his sources-you only by that method catalogue the material by which he expressed himself. The important and central thing in a philosopher is a kind of intuition akin to that of the artist, and differing fundamentally from the kind of activity you get in science.

To get to the detailed work of the congress, particularly the work done in the various sections of logic, theory of science, esthetic, ethic, general philosophy, and psychology, one can only say that it was very abundant and very unequal, considerable so far as the magnitude of the subjects raised was concerned, and very little so far as actual results obtained go. This sterility was in great part due to the defective organisation of the congress and to the persistent keeping to the tradition of a free choice of subjects and free individual communication, with the result that there is never time to really discuss in a serious way the subjects raised. For this reason the most interesting work of the congress was done at the general meetings in the afternoon, and we refer here to the lectures which attracted the greatest attention.

The mathematician Henri Poincaré examined the question which has been raised by Boutroux and certain other philosophers as to whether the laws of nature may change. In a world which evolves continually are the laws, i.e. the rules under which this evolution takes place, alone exempt from all variation. Such a conception could never be adopted by the man of science without denying even the possibility of science, but the philosopher has the right to pose the question. Imagine a world in which there was no difference of temperature. Certain laws would be discovered by the inhabitants, such as, for example, that water boils at a certain fixed pressure. Suppose, now, that in course of time this uniform temperature changed, all the laws would now change; water would boil at a different temperature, and so on. Now, however perfect might be the conductivity for heat of this planet, it would doubtless not be absolute, so that one day a physicist of genius might with his delicate instruments detect these imperceptible differences. A theory might then be erected that these differences of temperature had an effect on physical phenomena, and, finally, some bold speculator might affirm that the mean temperature of the world had varied in the past, and with it all physical laws. May there not be some physical entity as yet as entirely unknown to us as was temperature to the inhabitants of this 
imaginary world, which might vary and so create in the same way a change in all the laws?

Poincare found something analogous to this, at any rate, in the ideas now being brought forward on the subject of mechanics, and which were later in the congress put forward by Prof. Langevin, whose name is known in connection with work in radio-activity. It is now asserted that the laws of mechanics, once considered absolute, are not so. They must be changed, or at least enlarged. They are only approximately true for the velocities to which we are accustomed, and cease to be so for velocities comparable to that of light. One might say that, as a result of the constant dissipation of energy, the speed of bodies has much diminished, since their activity gets transformed into heat. Thus remounting back to the past, one would find an epoch when velocities comparable to that of light were not uncommon, and when, as a consequence, the classical laws of dynamics were not true. But if, on the other hand, we consider these laws as only approximate laws, and consider the laws of motion of molecules as the true laws, we can keep our faith in the immutability of laws in general. There is not, then, a sole law that we can enunciate with the certainty that it has always been true in the past. Nevertheless, there is nothing to hinder the man of science from keeping his faith in the principle of immutability, since no law can descend to the level of a secondary law without being replaced by another law more general and more comprehensive.

Prof. Durkheim, the celebrated sociologist, examined the question of "judgments of value" and social ideals. How do they arise? They cannot be accounted for on utilitarian principles, for they are often in direct conflict, not only with individual, but even with collective utility. They assert values which go beyond the practical. Must we, then, assume that the ideal is of a different nature from the world of fact. By no means. The ideal values are created in periods of great excitement, such as, for instance, the Renaissance and the French Revolution, when life for a time turns aside from the merely useful. Whilst the intenser life of such periods must of necessity soon die down, the judgments of value and the ideals they create survive into the periods of greater tranquillity, and it is from this that the apparent contradiction between the ideal and world of fact is born.

Prof. Ostwald, the exponent of "energetics," put forward a curious hypothesis in his paper " $\mathrm{La}$ Volonté et sa base physique" on the connection between the second law of thermodynamics and the mental phenomena of will. $\mathrm{He}$ started from general considerations drawn from Comte's and his own classification of the sciences. The notion of the antecedent and more general sciences finds a regular and systematic application in the subsequent and more special ones, while at the same time these latter require, in addition, the use of new conceptions. There is, for example, a mathematic and a geometry of chemistry, but not a chemistry of mathematics or a biology of physics. He then examined in this light the conception of energy. It appears for the first time in the domain of the physical sciences, and for that reason, while it has no application in the more general sciences of mathematics and logic, it should play an auxiliary part in biology, psychology, and sociology. The laws of the lower sciences cannot adequately explain the phenomena dealt with by the higher, but they provide the framework inside which the latter must work. How does this work out in detail? What meaning have the laws of energy applied to mental life? Just this-that whatever else mental life is, it has to work inside the limits of the second law of thermodynamics. Each individual is occupied all its life with the task of making circulate through its own body a part of the general course of "free" energy on its way to energy of a lower intensity; and further, as only part of this energy can be usefully employed, the rest being wasted in heat, so whatever else mental life may be it must first be directed towards getting as much out of this dissipation as possible. In the effort to increase this percentage, to save energy, comes, in Ostwald's opinion, the whole phenomena of the will. He does not pretend that the second law is an adequate explanation of all mental process, but it is the conditioning framework inside which all the rest must work. It is the dominating fast of mental life. It is this which makes the tremendous NO. 2 I 68 , VOL. 86$]$ importance of the will. All human activity is devoted to get the most out of this limited energy. (Incidentally, one may note the resemblance to Mach's conception of science as a process of economy of thought.) It is this conception of the "degradation of energy" which forms the basis of all the processes in which Schopenhauer saw manifestations of the fundamental will.

The English element at the congress was very small, being responsible for only eleven papers out of a total of 200. Among these the most important was Dr. Schiller's paper on error, which provoked, as any exposition of pragmatism always does at these meetings, a most lively discussion. There was also a paper by E. S. Russell on vitalism, and an interesting little note by Miss Constance Jones sketching out a new law of thought, which attempted to lead logic out of the barrenness of the law of identity, and which she enunciated in the phrase "Every subject of predication is an identity (of denotation) in diversity (of intension)."

The next congress will be held in London in 1915, under the auspices of the University, and it is hoped that this will create a greater interest in these meetings than has heretofore been the case in this country.

\section{RESEARCH AT THE NATIONAL PHYSICAI LABORATORY.1}

THE representative character of the work done at the National Physical Laboratory is well shown by the eight papers in the volume before us.

Nos. I and 2 are by Dr. Chree, and are entitled "Some Phenomena of Magnetic Disturbances at Kew" and "Discussion of Results Obtained at Kew Observatory with an Elster and Geitel Electrical Dissipation Apparatus from 1907-9."

No. 3 is the ninth report to the Alloys Research Committee of the Institution of Mechanical Engineers, on "The Properties of Some Alloys of Copper, Aluminium, and Manganese," by Messrs. Rosenhain and Lantsberry. This is a voluminous paper, and occupies more than half of the entire volume. It is the direct outcome of the eighth alloys research report on the properties of the alloys of copper and aluminium. The study of any ternary system of alloys is a work of considerable magnitude. As the authors remark (p. 65), "If we suppose for the sake of comparison that the study of alloys to the extent of one for every range of 2 per cent. in composition constitutes a sufficiently complete investigation of any system, then in any series of alloys of two metals, such as copper and aluminium, the study of some fifty alloys would meet these requirements, while the corresponding degree of completeness in the case of a ternary system would require the study of no less than I250 alloys." Very few industrial alloys, however, belong, strictly speaking, to a binary system. The majority are ternary, or even more complicated mixtures, and it is therefore of great industrial importance as well as of scientific interest that the study of such systems as the above should be undertaken.

The authors have not attempted to cover the entire field, but have contented themselves with experimenting on the addition of manganese to the most promising binary mixtures revealed in the eighth alloys report, which are situated at the ends of the system.

At the copper end they have found that certain ternary alloys present advantages over the best binary alloys, these consisting chiefly in a " higher yield point .. . a slightly higher ultimate stress and an undiminished ductility," in the static tests. A hot-rolled bar of a bronze containing approximately to per cent. of aluminium and $\mathrm{I}$ per cent. of manganese gave an ultimate stress of 42 tons per square inch with 30 per cent. elongation. In the dynamic tests, however, there is very little to choose between the binary and ternary systems. Three alloys were found to offer remarkable resistance to abrasion, and in this respect considerably surpassed ordinary tool steel, and as they machine quite readily they might very well be tried in cases where this property is of primary importance, e.g. in the form of turbine blades which have to withstand high velocity steam. As regards constitution, the authors have found that 1 The National Physical Laboratory: Collected Researches, Vol. VII. x 9 II, pp. iii +228 . 